\title{
Mechanism of Postarrhythmic Renal \\ Vasoconstriction in the Anesthetized Dog
}

\author{
Richard E. Katholi, SuZanne Oparil, Ferdinand Urthaler, and \\ Thomas N. James, Department of Medicine, University of Alabama Medical \\ Center, Birmingham, Alabama 35294
}

A B S TRACT The mechanism of postarrhythmic renal vasoconstriction was studied in $28 \mathrm{dogs}$ anesthetized with pentobarbital sodium (30 mg/kg i.v.). Rapid atrial or ventricular pacing or induction of atrial fibrillation were used to produce at least a $20 \%$ prompt decrease in cardiac output and mean arterial blood pressure. Return to control cardiac output and blood pressure occurred within $3 \mathrm{~min}$ after cessation of the arrhythmia, but renal blood flow remained significantly decreased $(26 \%)$ with gradual recovery by $17.7 \pm 6.6$ min. Infusion of phentolamine $(0.25 \mathrm{mg} / \mathrm{min})$ into the renal artery, intravenous hexamethonium ( $1 \mathrm{mg} / \mathrm{kg}$ ), adrenal demedullation, or cooling the cervical vagi prevented postarrhythmic renal vasoconstriction. In contrast, renal denervation, intravenous bretylium (10 $\mathrm{mg} / \mathrm{kg})$, intravenous atropine $(0.5 \mathrm{mg} / \mathrm{kg})$ or intrarenal SQ $20881(0.20 \mathrm{mg} / \mathrm{min})$ had no effect on postarrhythmic renal vasoconstriction. Intravenous propranolol $(0.5 \mathrm{mg} / \mathrm{kg})$ intensified postarrhythmic renal vasoconstriction. These data suggested that the postarrhythmic renal vasoconstrictive response required intact vagi and was due to alpha adrenergic stimulation by adrenal catecholamines. However, femoral arterial catecholamine levels were not elevated above control during postarrhythmic renal vasoconstriction. We therefore sought local vascular pathways by which catecholamines might reach the kidneys. An adrenorenal vascular network was found in each dog. Collection of catecholamines from these vessels during postarrhythmic renal vasoconstriction in six dogs revealed catecholamine concentrations threefold higher than simultaneously collected femoral arterial catecholamines levels. Because ligation of these vessels abolished postarrhythmic renal vasoconstriction in each dog, we conclude that postarrhythmic renal vasoconstriction is due to adrenal catecholamines reaching the

Dr. Oparil is an Established Investigator of the American Heart Association.

Received for publication 18 July 1978 and in revised form 26 January 1979. kidneys through an adreno-renal vascular network and that the response requires intact vagi.

\section{INTRODUCTION}

Abrupt changes in cardiac rhythm usually result in a fall in cardiac output and arterial blood pressure (1). Blood flow to most vascular beds decreases when the arterial pressure drops during rapid supraventricular or ventricular arrhythmias (2). The immediate peripheral compensatory vasoconstriction resulting from a fall in systemic blood pressure during an arrhythmia is due to an increase in sympathetic tone (2). However, renal blood flow in the anesthetized dog remains decreased for a considerably longer period of time after an arrhythmia, despite a return to control levels of flow in other vascular beds (3). Because the renin-angiotensin system and the sympathetic nervous system are potent renal arteriolar vasoconstrictors which are activated by a decrease in blood pressure, one could postulate a role for either in controlling renal blood flow after an arrhythmia (4-6). The purpose of this study was to elucidate the mechanism of postarrhythmic renal vasoconstriction in the anesthetized dog.

\section{METHODS}

Experiments were performed on 28 mongrel dogs (17-22.5 $\mathrm{kg}$ ) of either sex anesthetized with intravenous pentobarbital sodium $(30 \mathrm{mg} / \mathrm{kg})$. Positive pressure ventilation was maintained through a cuffed endotracheal tube and ventilatory volume per minute was adjusted according to a continuously monitored end-tidal $\mathrm{CO}_{2}$ concentration obtained with a gas analyzer (LB-2 Beckman, Beckman Instruments, Inc., Electronic Instruments Div., Schiller Park, Ill.). A median sternotomy and celiotomy were performed. Electromagnetic flow probes (Biotronex Laboratory, Inc., Kensington, Md.) (14-16 and $2.5-3.5 \mathrm{~mm}$ in diameter) were placed $2 \mathrm{~cm}$ above the aortic valve for calculation of cardiac output and around either right or left renal artery for calculation of renal blood flow. Because of the prolonged vasoconstriction that occurs with clamping of the renal artery, zero flow was determined by a brief occlusion of the renal artery distal to the probe immediately after its application and at the end of the experiment. These flow probes were calibrated after each experi- 
ment using a cow aorta for the larger and a segment of canine femoral artery for the smaller probes. The 14-16-mm probes were calibrated using five measured flows ranging from 0.8 to 4.5 liters $/ \mathrm{min}$. The $2.5-3.5-\mathrm{mm}$ probes were calibrated using five measured flows ranging from 90 to 430 $\mathrm{ml} / \mathrm{min}$. Using these five calibration points (recorded in $\mathrm{mm}$ ) a first-order linear regression model was fit and equations were derived for calculations of flow in milliliters per minute. The same probes were used throughout this study and for these five measured flows, each probe was found to consistently record flows with $\pm 5 \%$ accuracy.

A catheter $(0.075 \mathrm{~cm}$ outer diameter $)$ was placed into the right atrium via the external jugular vein for measurement of mean right atrial pressure. A catheter $(0.075 \mathrm{~cm}$ outer diameter) was placed above the aortic valve, via the internal mammary artery to avoid damage to nerves of the carotid arteries, for measurement of central aortic arterial pressure. By means of a steel guidewire, a catheter $(0.025 \mathrm{~cm}$ outer diameter $)$ was inserted into the left renal artery by penetrating the contralateral aortic wall to avoid injury to periarterial renal nerves. The guidewire was removed and the catheter was sutured to the aortic wall for stability. This catheter was used for intrarenal drug infusion. Catheters were also appropriately placed in the femoral artery and in the inferior vena cava with tip just cephalad to the adrenal veins for sampling of arterial blood and adrenal venous effluent for plasma catecholamines and renin activity. The inferior vena caval catheter was also used for intravenous drug administration. Electrodes were sewn to the right atrium and right ventricle for bipolar electrogram recordings or atrial and ventricular electrical activity and for pacing the heart.

After the animal was prepared, no measurements were made for at least $1 \mathrm{~h}$ to allow for stabilization. When supplemental anesthesia was required during the experiment, no measurements were made subsequently for at least $30 \mathrm{~min}$ to allow full return to control stability. The preparations remained stable hemodynamically over a number of hours. When interventions (drug administration, vagal cooling, renal denervation, or adrenal demedullation) was performed during the experiment, hemodynamic stability was judged from at least $15 \mathrm{~min}$ of observation. Hemodynamic measurements were regularly made before, during, and after induced cardiac rhythm changes. The aortic and renal blood flows were determined by measuring the area under the flow curves (recorded at paper speed $50 \mathrm{~mm} / \mathrm{s}$ ) by planimetry of consecutive beats over 20 -s periods. Using the planimetric method of measuring the area under the flow curves avoids measurements of electrical artifacts on flow probe shifts because the examiner can choose a 20-s recording during the specified minute's period which is free of these defects. The mean value of How (area under curves in square millimeters/millimeters of time) in millimeters was then converted to flow in milliliters per minute using the equations derived from a first-order linear regression model of the five points obtained during flow probe calibration. When flow values from an experiment were determined by this method on different days, the coefficient of variation of these values was $2.3 \%$. Heart rates, blood pressures or blood flows reported during sinus rhythm (control and postarrhythmic periods) are the mean of a 20 -s period obtained during a specified minute's period. Control period was the minute before inducing an arrhythmia. Because of their variable nature, values reported during an experimental arrhythmia are the mean of 20 -s periods obtained from each of the 3 min of the rhythm disturbance. The postarrhythmic renal blood flow reported is the mean of a 20 -s period of the fourth postarrhythmic minute of flow (measured at a time when cardiac output and mean arterial blood pressure had returned to control values). Total and renal vascular resistances were calculated by the formula: Resistance $=$ (mean arterial pressure - mean right atrial pressure in millimeters $\mathrm{Hg} / \mathrm{flow}$ in milliliters per minute).

From pilot studies we found that if atrial fibrillation (produced by electrical stimulation) lasted at least $4 \mathrm{~min}$, a reproducible postarrhythmic decrease in renal blood flow was observed which lasted $\geq 5$ and as long as $30 \mathrm{~min}$ beyond cessation of the arrhythmia. If the arrhythmia lasted $<4 \mathrm{~min}$, this postarrhythmic renal vasoconstriction was not readily seen. For these reasons atrial fibrillation was the arrhythmia most frequently used in subsequent experiments and six min was chosen as its minimal duration. Atrial fibrillation was induced in all 28 dogs by a $2-\mathrm{ms}, 20-40$-cycles/s, $7-10-\mathrm{V}$ stimulus to the atrium through the atrial electrode or to the right atrial appendage with an alligator clip. The arrhythmia usually reverted spontaneously to sinus rhythm after a few minutes. If atrial fibrillation had not lasted about $6 \mathrm{~min}$ as was planned, another stimulus was given. If atrial fibrillation persisted longer than $6 \mathrm{~min}$, it was easily converted to sinus rhythm by cooling the epicardium in the region of the sinus node. In 13 animals the hemodynamic responses to atrial fibrillation, to atrial pacing, and to ventricular pacing were compared.

In nine dogs plasma samples for norepinephrine, epinephrine, and renin activity were drawn before atrial fibrillation (control), during atrial fibrillation, immediately after fibrillation, 4 min after fibrillation, and then after renal blood flow had returned to control values. Plasma norepinephrine and epinephrine were measured using a modification of the radioenzymatic method of Passon and Peuler (7). This method (The Upjohn Co., Kalamazoo, Mich.) of measuring plasma catecholamines is sensitive and specific. This catecholamine assay is linear from 0 to $3,000 \mathrm{pg} /$ assay. The statistics for standards supplied by the manufacturer assayed on seven different days in our laboratory reveal a coefficient of variation for norepinephrine of $5.4 \%$ and epinephrine of $8.8 \%$. Plasma renin activity was assessed by measuring angiotensin I generated at $37^{\circ} \mathrm{C}$ and $\mathrm{pH} 7.4$ according to the method of Haber et al. (8). In six dogs conversion of angiotensin I to angiotensin II was blocked by SQ 20881 (E. R. Squibb \& Sons, Inc., New Brunswick, N. J.) delivered intrarenally as a 5-mg bolus followed by a continuous infusion at $0.20 \mathrm{mg} / \mathrm{min}$ for $30 \mathrm{~min}$ using a Harvard pump (Harvard Apparatus Co., Inc., Millis, Mass.). The infusion was begun before and continued during and after a bout of atrial fibrillation. Animals treated with SQ 20881 were tested for completeness of converting-enzyme inhibition by administering $10-\mu \mathrm{g}$ doses of angiotensin I intravenously and observing for a pressor response. In six dogs alpha adrenergic receptor blockade was produced with intrarenal infusions of phentolamine $(2.5 \mathrm{mg}$ bolus followed by a continuous infusion at $0.25 \mathrm{mg} / \mathrm{min}$ for $30 \mathrm{~min}$ ). When intrarenal infusions were done, control responses to atrial fibrillation were obtained first by using an infusion of only the diluting vehicle; during each 30-min experiment this procedure infused $<1$ meq of sodium. In six dogs the renal vascular response to atrial fibrillation was measured after the intravenous administration of $0.5 \mathrm{mg} / \mathrm{kg}$ of propranolol.

In six dogs the renal vascular response to atrial fibrillation was measured during temporary blockade of the vagi, accomplished by cooling the cervical portion of the nerve to near $0^{\circ} \mathrm{C}$. Blockade was considered complete when vagal nerve stimulation $(2 \mathrm{~ms}, 20$ cycles $/ \mathrm{s}$, threshold voltage) caused no sinus slowing. In six dogs the renal vascular response to atrial fibrillation was also measured after the intravenous administration of $0.5 \mathrm{mg} / \mathrm{kg}$ atropine. In six dogs acute renal denervation was produced by stripping the renal arterial adventitia and painting the renal artery with a solution containing $10 \%$ phenol in ethanol. Bretylium tosylate $(10 \mathrm{mg} / \mathrm{kg})$ 
was administered in six dogs. Bretylium-treated animals were tested for completeness of neural blockade by stimulating the right stellate ganglion and determining that the control sinus acceleration had been abolished. Hexamethonium chloride $(1 \mathrm{mg} / \mathrm{kg}$ ) was administered intravenously to six dogs; completeness of ganglionic blockade was tested by stimulating the right vagus nerve and determining that the control decrease in heart rate was attenuated by at least $90 \%$. Unilateral adrenal demedullation was carried out in six dogs either by adrenalectomy (three dogs) or bisecting the gland along its long axis in situ and curettage of the darker central medullary tissue (three dogs).

On completion of the experiment, we administered heparin sodium $(150 \mu / \mathrm{kg})$ to facilitate injection of the adrenal arteries or renal arteries with India ink or Microfil (Canton Bio-Medical Products, Inc., Boulder, Colo.). This permitted us to examine in detail the vessels between the adrenal gland and the kidney. Specimens were then preserved in $10 \%$ neutral formalin and subsequently had the fatty tissue dissected, after which they were dehydrated in graduated increasing concentrations of ethyl alcohol and finally immersed in colorless methyl salicylate. This standard anatomical method of injecting and clearing provided an optimal preparation depicting the vascular anatomy in three dimensions for a semitransparent specimen.

Numerical results are expressed as means $\pm 1 \mathrm{SE}$. Because a control response was always performed before each intervention, the changes (preintervention vs. intervention) were analyzed using the paired Student's $t$ test. Changes are reported as significant if the $P$ value was $<0.05(9)$. For graphical presentation the data were normalized by expressing it in percentage of change.

\section{RESULTS}

Hemodynamic changes caused by arrhythmia. Table I summarizes the hemodynamic effects of atrial fibrillation for 6-min periods in 27 dogs (experience with the 28th dog is described later). Fig. 1 depicts the results of a representative experiment. Atrial fibrillation caused a $22 \%$ reduction in cardiac output with an associated $20 \%$ decrease in mean arterial blood pressure. During the period of atrial fibrillation, renal blood flow was decreased by $29 \%$. The percentage of reduc-

TABLE I

Systemic and Renal Hemodynamic Changes during and after Atrial Fibrillation in 27 Anesthetized Dogs

\begin{tabular}{lccc}
\hline & Control & During & After 4 min \\
\hline MABP, $m$ m Hg & $107 \pm 4$ & $87 \pm 3^{*}$ & $109 \pm 4$ \\
HR, beats/min & $155 \pm 5$ & $248 \pm 7^{*}$ & $154 \pm 5$ \\
CO, liters/min & $2.62 \pm 0.12$ & $2.04 \pm 0.12^{*}$ & $2.66 \pm 0.12$ \\
TPR, $R U$ & $40.3 \pm 1.7$ & $41.3 \pm 1.8$ & $40.4 \pm 1.8$ \\
RBF, $m l / m i n$ & $253 \pm 11$ & $179 \pm 8^{*}$ & $188 \pm 7^{*}$ \\
RVR, $r u$ & $0.42 \pm 0.02$ & $0.47 \pm 0.02^{*}$ & $0.57 \pm 0.02^{*}$ \\
\hline
\end{tabular}

Values are means $\pm \mathrm{SE}$. MABP, mean arterial blood pressure; $\mathrm{HR}$, heart rate; CO, cardiac output; RBF, renal blood flow; TPR, total peripheral resistance expressed in Resistance Units (RU); RVR, renal vascular resistance expressed in resistance units (ru).

* Change from control value was significant $(P<0.001)$. tion of renal blood flow was significantly greater than $(P<0.01)$ the reduction in cardiac output. Mean right atrial pressures were found to increase $(P<0.001)$ from $1.5 \pm 0.18 \mathrm{~mm} \mathrm{Hg}$ during control to $2.4 \pm 0.19 \mathrm{~mm} \mathrm{Hg}$ during atrial fibrillation and return to control levels $1.5 \pm 0.19 \mathrm{~mm} \mathrm{Hg}$ by $4 \mathrm{~min}$ after the arrhythmia. Renal vascular resistance was significantly increased $(P$ $<0.001$ ) above control during the arrhythmia, but total peripheral resistance was not.

The first few sinus beats after cessation of the atrial fibrillation showed a marked overshoot of cardiac output and blood pressure with an associated increase in renal blood flow. Within 1-3 min after the arrhythmia, cardiac output and mean arterial blood pressure returned to and stabilized at control levels. However, renal blood flow progressively decreased still further, eventually reaching $74 \%$ of control. Renal blood flow in the $27 \mathrm{dogs}$ then slowly recovered and reached control levels $17.7 \pm 6.6 \mathrm{~min}$ after cessation of the arrhythmia.

In six dogs bouts of atrial fibrillation $(6 \mathrm{~min})$ were induced every $15 \mathrm{~min}$ for $2 \mathrm{~h}$. Renal blood flow remained constantly decreased to $65-75 \%$ of control until the bouts of arrhythmia were discontinued. There was no evidence of progressive deminution of renal blood flow or of any form of refractoriness by the renal circulation to the consequences of repetitive bouts of arrhythmia.

In one of the 28 dogs, five episodes of atrial fibrillation did not result in postarrhythmic renal vasoconstriction. However, in this animal ventricular rate during atrial fibrillation increased only from control of 172 to 210 beats/min with a concomitant decrease in cardiac output of only $4 \%$ and decrease in mean arterial blood pressure of $9 \%$. When this dog was subjected to rapid atrial or ventricular pacing $(250 \mathrm{stimul} / \mathrm{min})$ there was respectively a 20 or $26 \%$ decrease in cardiac output and a 19 or $23 \%$ decrease in mean arterial blood pressure, and then the usual postarrhythmic renal vasoconstriction was observed.

12 other dogs were subjected to atrial and ventricular pacing at various rates $(220-270 \mathrm{stimuli} / \mathrm{min})$ as well as to atrial fibrillation (at different times), and the systemic and renal hemodynamic effects of the three interventions were compared. Comparison of the percentage of decrease in cardiac output with the percentage of decrease in renal blood flow during atrial or ventricular pacing revealed that the reduction in renal blood flow was significantly greater than $(P<0.01)$ the reduction in cardiac output, exactly as was observed during atrial fibrillation. All three of these experimental rhythms resulted in postarrhythmic decrease in renal blood flow when at least a $20 \%$ reduction in cardiac output and a concomitant $16 \%$ decrease in mean arterial pressure was achieved during the experimental arrhythmia (Figs. 2 and 3). 


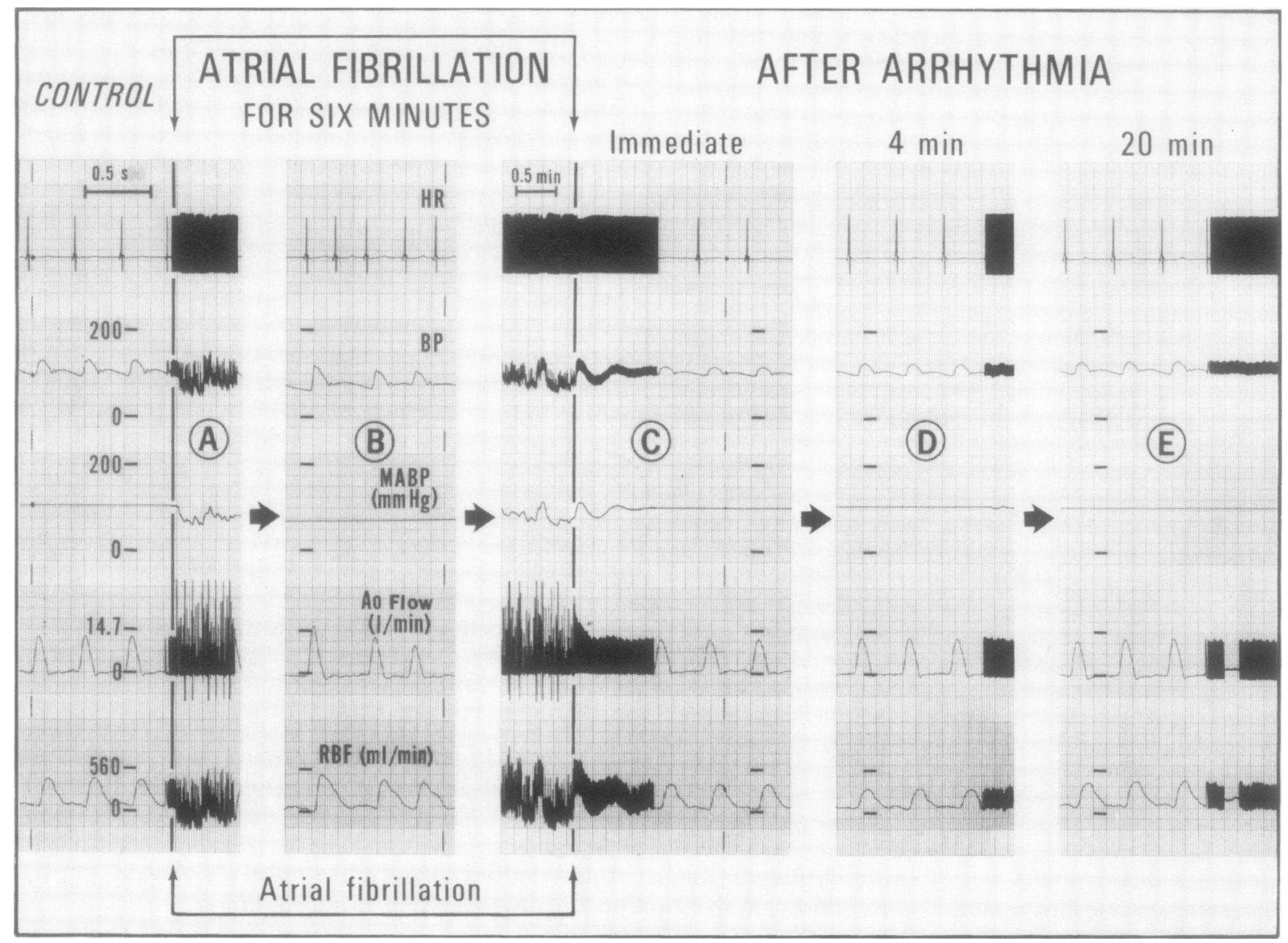

FIGURE 1 Characteristic example of changes in ventricular heart rate (HR, represented by a bipolar ventricular electrogram), phasic (BP) and mean arterial blood pressure (MABP), aortic flow (Ao Flow or cardiac output), and renal blood flow (RBF) during and after 6 min of atrial fibrillation in one dog. (A) An immediate decrease in arterial blood pressure coincides with onset of atrial fibrillation. (B) Recording of atrial fibrillation at $50 \mathrm{~mm} / \mathrm{s}$. (C) With the first few beats upon cessation of atrial fibrillation, there is overshoot of aterial blood pressure and cardiac output with an associated increase in renal blood flow. (D) By 4 min postarrhythmia arterial blood pressure and cardiac output are at control levels and postarrhythmic renal blood flow is $73 \%$ of control. (E) Renal blood flow has returned to control levels. The calibrations remain the same throughout the figure.

Plasma catecholamines and renin activity. Table II summarizes the changes in plasma catecholamine concentration and renin activity in blood samples drawn from the inferior vena cava and femoral artery during and after 6 min of atrial fibrillation in nine dogs. In all nine animals atrial fibrillation produced at least a $20 \%$ reduction in cardiac output and mean arterial blood pressure, and the usual postarrhythmia renal vasoconstriction. A twofold elevation from control levels of plasma norepinephrine and epinephrine was found in inferior vena cava samples (taken from just above the adrenal veins) during the arrhythmia, and the catecholamines remained significantly increased above control levels when measured during the immediate postar- rhythmic period. However, by the 4 th min postarrhythmia inferior vena caval catecholamines concentrations had returned to control, as had cardiac output and mean arterial blood pressure, whereas postarrhythmic renal vasoconstriction was still maximal.

Femoral arterial catecholamines were significantly elevated above control levels only during the immediate postarrhythmic period (Table II). Comparison of inferior vena caval and femoral arterial catecholamine samples drawn simultaneously revealed a significant veno-arterial difference (inferior vena caval catecholamine concentration was twofold higher) during atrial fibrillation $(P<0.01)$. Plasma renin activity measured from either sampling site was significantly elevated 


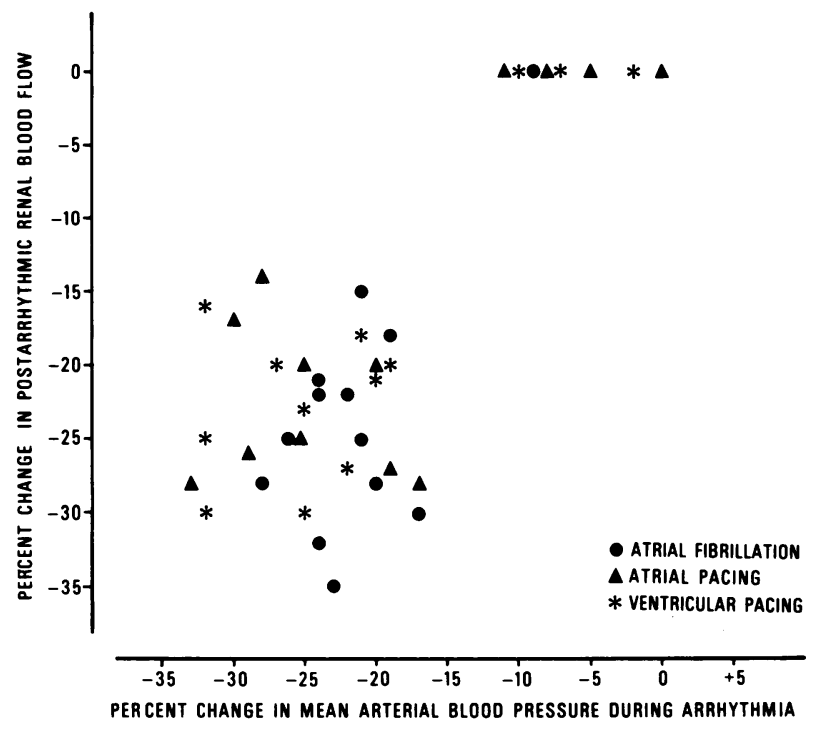

FIGURE 2 Relationship between the percentage of change in mean arterial blood pressure during arrhythmia (atrial fibrillation, atrial pacing, and ventricular pacing) and the percentage of change in renal blood flow postarrhythmia in 13 dogs. Measurements during control period and after arrhythmias represent the mean value over $1 \mathrm{~min}$ while measurements during an arrhythmia represent the mean value observed for the initial $3 \mathrm{~min}$ of the arrhythmia. There is a virtual threshold for blood pressure decrement necessary to cause postarrhythmic renal vasoconstriction. In the 15 other dogs in which only atrial fibrillation was induced, a similar decrease in mean arterial blood pressure was observed.

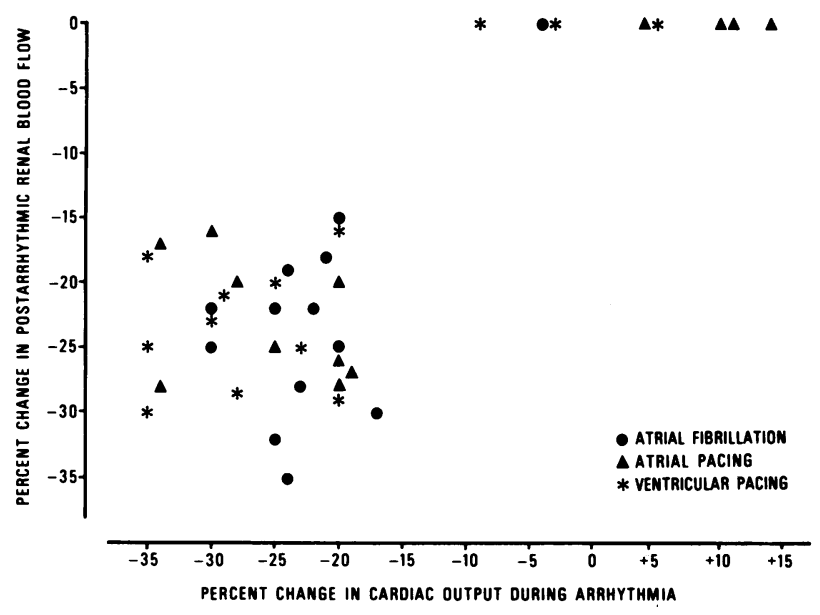

FIGURE 3 Relationship between the percentage of change in cardiac output during atrial fibrillation, atrial pacing, and ventricular pacing and the percentage of change in renal blood flow postarrhythmia in 13 dogs. A minimum decrement is necessary before the lowered output causes postarrhythmic renal vasoconstriction. In the 15 other dogs in which only atrial fibrillation was induced, a similar decrease in cardiac output was observed.

from control during and immediately after atrial fibrillation $(P<0.01)$, but no significant veno-arterial differences were noted (Table II).

Intrarenal infusion of the converting enzyme inhibitor SQ 20881 in six dogs, caused a $17 \%$ increase in

TABLE II

Plasma Norepinephrine Concentration (NE), Plasma Epinephrine Concentration (E), and Plasma Renin Activity (PRA) Drawn from the Inferior Vena Cava (IVC) and the Femoral Artery (FA) during and after a bout of Atrial Fibrillation in Nine Anesthetized Dogs

\begin{tabular}{|c|c|c|c|c|c|}
\hline \multirow[b]{2}{*}{ Sample and site } & \multirow{2}{*}{$\begin{array}{l}\text { Control before } \\
\text { arrhythmia }\end{array}$} & \multirow{2}{*}{$\begin{array}{l}\text { During atrial } \\
\text { fibrillation }\end{array}$} & \multicolumn{3}{|c|}{ Time after arrhythmia } \\
\hline & & & Immediate & $4 \mathrm{~min}$ & $25 \mathrm{~min}$ \\
\hline IVC & $299.3 \pm 46.2$ & $604.8 \pm 65.7^{*}$ & $427.8 \pm 58.9 \ddagger$ & $371.3 \pm 50.4$ & $350.7 \pm 46.8$ \\
\hline $\mathrm{NE}, p g / m l$ & NS & $P<0.01$ & NS & NS & NS \\
\hline FA & $212.4 \pm 37.2$ & $298.6 \pm 46.4$ & $398.8 \pm 58.3^{*}$ & $234.9 \pm 52.2$ & $228.1 \pm 40.8$ \\
\hline IVC & $364.9 \pm 49.0$ & $724.5 \pm 68.9^{*}$ & $557.8 \pm 62.8 \ddagger$ & $448.8 \pm 59.1$ & $324.3 \pm 43.9$ \\
\hline $\mathrm{E}, p g / m l$ & NS & $P<0.01$ & NS & NS & NS \\
\hline FA & $258.8 \pm 46.9$ & $317.0 \pm 51.2$ & $430.8 \pm 52.8 \ddagger$ & $309.0 \pm 49.6$ & $240.7 \pm 44.6$ \\
\hline IVC & $6.4 \pm 1.2$ & $11.8 \pm 1.6^{*}$ & $10.5 \pm 1.5^{*}$ & $8.0 \pm 1.3$ & $5.6 \pm 1.1$ \\
\hline PRA, $n g / m l / h$ & NS & NS & NS & NS & NS \\
\hline FA & $5.2 \pm 1.1$ & $9.7 \pm 1.4^{*}$ & $9.1 \pm 1.4^{*}$ & $6.3 \pm 1.1$ & $5.1 \pm 1.1$ \\
\hline
\end{tabular}

Values are mean $\pm \mathrm{SE}$. The tip of the inferior vena caval catheter was just cephalad to the adrenal veins for sampling of adrenal venous effluent. Maximal postarrhythmic renal vasoconstriction was present when the 4-min samples were drawn. Postarrhythmic renal blood flow had returned to control levels of flow when the 25-min samples were drawn.

$* P<0.01$ refer to changes compared to control.

$\ddagger P<0.05$ refer to changes compared to control. 
TABLE III

Effects of SQ 20881 (0.20 $\mathrm{mg} / \mathrm{min})$ and Phentolamine $(0.25 \mathrm{mg} / \mathrm{min})$ on Systemic and Renal Hemodynamic Changes during and after Atrial Fibrillation

\begin{tabular}{|c|c|c|c|c|c|c|c|}
\hline & \multicolumn{3}{|c|}{ Pre-SQ 20881} & \multirow[b]{2}{*}{$(n=6)$} & \multicolumn{3}{|c|}{ SQ 20881} \\
\hline & Control & During & After & & Control & During & After \\
\hline $\mathrm{MABP}, \mathrm{mm} \mathrm{Hg}$ & $101 \pm 7$ & $82 \pm 7^{*}$ & $102 \pm 7$ & & $97 \pm 7$ & $80 \pm 7^{*}$ & $97 \pm 7$ \\
\hline HR, beats/min & $159 \pm 9$ & $262 \pm 11^{*}$ & $158 \pm 9$ & & $165 \pm 9$ & $265 \pm 11^{*}$ & $167 \pm 9$ \\
\hline $\mathrm{CO}$, liters/min & $2.25 \pm 0.20$ & $1.82 \pm 0.20 *$ & $2.27 \pm 0.20$ & & $2.29 \pm 0.20$ & $1.81 \pm 0.20^{*}$ & $2.28 \pm 0.20$ \\
\hline $\mathrm{TPR}, R U$ & $44.0 \pm 3.0$ & $43.4 \pm 3.0$ & $44.0 \pm 3.0$ & & $41.8 \pm 3.0$ & $42.5 \pm 3.0$ & $41.7 \pm 3.0$ \\
\hline $\mathrm{RBF}, \mathrm{ml} / \mathrm{min}$ & $215 \pm 13$ & $155 \pm 12^{*}$ & $163 \pm 12^{*}$ & & $251 \pm 13 \ddagger$ & $183 \pm 12^{*}$ & $191 \pm 12^{*}$ \\
\hline $\mathrm{RVR}, r u$ & $0.46 \pm 0.02$ & $0.51 \pm 0.02 *$ & $0.61 \pm 0.02 *$ & & $0.38 \pm 0.02 \ddagger$ & $0.42 \pm 0.02^{*}$ & $0.50 \pm 0.02 *$ \\
\hline
\end{tabular}

Values are mean $\pm \mathrm{SE}$. The number of experiments is given after each subheading. For abbreviations see Table $\mathrm{I}$.

$* P<0.001$ refers to paired $t$ test comparing changes during and after atrial fibrillation with control values.

$\ddagger P<0.01$ refers to paired $t$ test comparing control values before and after the administration of SQ 20881 or phentolamine.

renal blood flow and a $17 \%$ decrease in renal vascular resistance compared to pre-SQ 20881 control measurements (Table III). Intrarenal infusion of SQ 20881 coincident with bouts of atrial fibrillation which decreased cardiac output and mean artificial blood pressures by at least $20 \%$, did not prevent a postarrhythmic decrease in renal blood flow (Fig. 4).

Control hemodynamic measurements during intrarenal phentolamine infusion compared to pre-phentolamine control values in six dogs showed a $13 \%$ decrease in mean arterial pressure, an $8 \%$ increase in
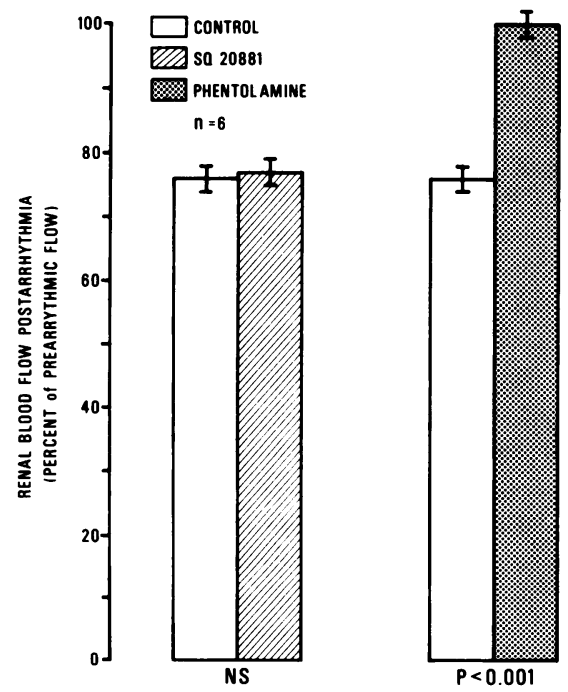

FIGURE 4 Effect of intrarenal infusion of SQ $20881(0.20$ $\mathrm{mg} / \mathrm{min})$ or phentolamine $(0.25 \mathrm{mg} / \mathrm{min})$ on postarrhythmic renal blood flow (percentage of prearrhythmic flow), compared with control response. Renal blood flow measurements represent the mean value during $1 \mathrm{~min}$ immediately before atrial fibrillation, and during the 4 th $\mathrm{min}$ of the postarrhythmic period (a time when cardiac output and mean arterial blood pressure had returned to base-line levels and maximal postarrhythmic renal vasoconstriction was present). heart rate, an $18 \%$ increase in cardiac output, a $30 \%$ increase in renal blood flow, a $29 \%$ decrease in total peripheral resistance, and a $32 \%$ decrease in renal vascular resistance (Table III). During atrial fibrillation renal blood flow decreased in proportion to the decreased cardiac output, rather than to a greater degree as seen with control response. In addition, intrarenal infusion of phentolamine prevented the development of postarrhythmic renal vasoconstriction (Fig. 4).

The administration of propranolol (Table IV) in six dogs caused a $13 \%$ decrease in heart rate, a $28 \%$ decrease in cardiac output, a $21 \%$ decrease in renal blood flow, a $40 \%$ increase in total peripheral resistance, and a $31 \%$ increase in renal vascular resistance compared to pre-propranolol control measurements. Of note, postarrhythmic renal blood flow after propranolol administration was decreased $35 \%$ in contrast to the $25 \%$ decrease observed during control response. This postarrhythmic renal vasoconstriction in the presence of propranolol was significantly greater $(P<0.01)$.

Neural and adrenal medullary function. Cooling the cervical vagi did not significantly change the control hemodynamics or the hemodynamic responses in six dogs during atrial fibrillation (Table $\mathrm{V}$ and Fig. 5). As seen with control responses and with vagal cooling, the percentage of reduction in renal blood flow during the arrhythmia was significantly greater than $(P<0.01)$ the percentage of decrease in cardiac output. In contrast, cooling the cervical vagi did prevent the development of postarrhythmic renal vasoconstriction (Table $\mathrm{V}$ and Fig. 6). Upon rewarming the vagi, postarrhythmic reduction in renal blood flow was again seen.

The administration of atropine in six dogs did not significantly change the control hemodynamics or the hemodynamic responses during atrial fibrillation. As seen with control responses and after atropine, the percentage of reduction in renal blood flow during the arrhythmic was significantly greater than $(P<0.01)$ the 
TABLE III (Continued)

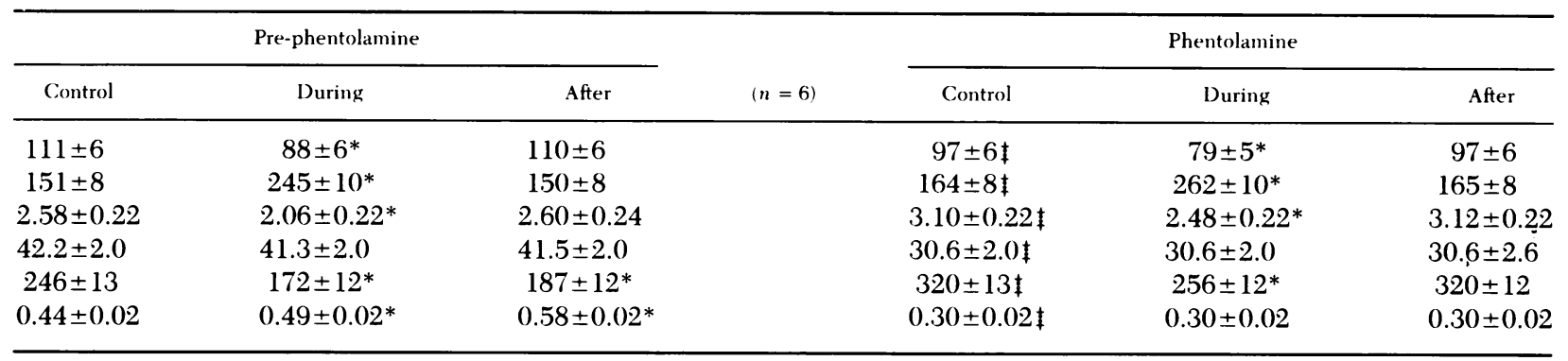

percentage of decrease in cardiac output. Additionally, atropine administration did not alter postarrhythmic renal vasoconstriction (Table $\mathrm{V}$ ).

Acute renal denervation in six dogs caused a $15 \%$ increase in control renal blood flow (Table IV) and altered the hemodynamic response of the kidney to arrhythmia-induced hypotension. During the arrhythmia, renal blood flow decreased in proportion to the decreased cardiac output, rather than to a greater degree as seen with control (Table IV and Fig. 5). However upon cessation of the arrhythmia, the magnitude of the postarrhythmic decrease in renal blood flow was similar to that seen when the renal nerves were intact (Table IV and Fig. 6). Thus, renal denervation did not alter the postarrhythmic renal vasoconstriction.

The administration of bretylium tosylate to six other dogs resulted in a $17 \%$ decrease in blood pressure, an $11 \%$ decrease in heart rate, and a $14 \%$ decrease in renal vascular resistance compared to pre-bretylium control measurements (Table VI). During atrial fibrillation (Fig. 5) proportional decreases in cardiac output and renal blood flow similar to those seen with renal denervation were observed. Similarly, postarrhythmic renal vasoconstriction occurred despite bretylium treatment (Fig. 6). This postarrhythmic decrease in renal blood flow was of the same magnitude as seen before bretylium treatment.

Administration of hexamethonium chloride in six animals resulted in a $30 \%$ decrease in mean blood pressure, a $20 \%$ decrease in heart rate, a $19 \%$ decrease in cardiac output, an $11 \%$ decrease in renal blood flow, a $13 \%$ decrease in total peripheral resistance, and an $18 \%$ decrease in renal vascular resistance compared to prehexamethonium control measurements (Table VI). During atrial fibrillation (Fig. 5) a proportional decrease in cardiac output and renal blood flow similar to that seen after either renal denervation or bretylium was observed. However, no postarrhythmic renal vasoconstriction was observed after administration of hexamethonium (Fig. 6). This constrasts with the results of renal denervation and bretylium treatment in which postarrhythmic renal vasoconstriction was preserved.

Because these studies suggested that adrenal cate- cholamines played a major role in postarrhythmic renal vasoconstriction, a flow probe was placed on each renal artery in six dogs. After a control bout of atrial fibrillation, acute unilateral adrenal demedullation was carried out. During the arrhythmia, renal blood flow was decreased equally on both sides. However, upon cessation of the atrial fibrillation, the kidney adjacent to the medullated adrenal gland showed no postarrhythmic renal vasoconstriction (Fig. 6), while the contralateral kidney showed postarrhythmic renal vasoconstriction indistinguishable from the control response.

Anatomical studies of vascular connections between the adrenal gland and the kidney. Postarrhythmic renal vasoconstriction appeared to be mediated primarily by alpha adrenergic stimulation by adrenal catecholamines, yet femoral arterial catecholamine levels were not elevated at a point in time $4 \mathrm{~min}$ postarrhythmia, when maximal postarrhythmic renal vasconstriction was present. This suggested the possibility that adrenal catecholamines might reach the kidneys via localized pathways without entering the systemic circulation and thus directly affect control of the renal circulation.

In 17 dogs the adrenal arteries, renal arteries, and renal veins were identified and selectively cannulated in situ postmortem. The adrenal vein was tied off at its point of entry into the inferior vena cava. Ligation of the tissue between the renal artery and adrenal gland was also done to tie off vessels which sometimes branch from the renal artery to supply the adrenal gland. Selective injection of India ink into the adrenal artery in four dogs resulted in staining of the adrenal gland (particularly the medulla) but also fulfilled a network of vessels (rete) in the perirenal fat. Upon bisecting the kidney along its long axis, extensive staining was found in the renal cortex with some staining of the renal medulla. Selective injection of India ink into the renal artery in four animals resulted in the filling of this same network of perirenal-adrenal vessels and upon bisecting the adrenal gland along its long axis, its medulla was found to be stained selectively.

Having seen this network of vessels between the adrenal gland and kidney, we then prepared nine specimens using selective injection of Microfil into the 
TABLE IV

Effects of Propranolol (0.5 mg/kg) and Renal Denervation on Systemic and Renal Hemodynamic Changes during and after Atrial Fibrillation

\begin{tabular}{|c|c|c|c|c|c|c|c|}
\hline & \multicolumn{3}{|c|}{ Pre-propranolol } & \multirow[b]{2}{*}{$(n=6)$} & \multicolumn{3}{|c|}{ Propranolol } \\
\hline & Control & During & After $4 \mathrm{~min}$ & & Control & During & After $4 \mathrm{~min}$ \\
\hline $\mathrm{MABP}, m m \mathrm{Hg}$ & $112 \pm 6$ & $89 \pm 5^{*}$ & $112 \pm 6$ & & $114 \pm 7$ & $89 \pm 6^{*}$ & $112 \pm 6$ \\
\hline HR, beats/min & $150 \pm 7$ & $248 \pm 9^{*}$ & $151 \pm 7$ & & $130 \pm 7 \ddagger$ & $202 \pm 8^{*}$ & $132 \pm 7$ \\
\hline $\mathrm{CO}$, liters $/$ min & $2.75 \pm 0.21$ & $2.23 \pm 0.20^{*}$ & $2.79 \pm 0.21$ & & $1.98 \pm 0.20 \ddagger$ & $1.54 \pm 0.19 *$ & $1.95 \pm 0.20$ \\
\hline TPR, $R U$ & $40.0 \pm 3.0$ & $38.6 \pm 3.0$ & $39.4 \pm 3.0$ & & $56.6 \pm 4.0 \ddagger$ & $55.8 \pm 4.1$ & $56.4 \pm 4.0$ \\
\hline $\mathrm{RBF}, \mathrm{ml} / \mathrm{min}$ & $260 \pm 13$ & $184 \pm 12^{*}$ & $195 \pm 12^{*}$ & & $205 \pm 12 \ddagger$ & $139 \pm 11^{*}$ & $134 \pm 11^{*}$ \\
\hline RVR, $r u$ & $0.42 \pm 0.02$ & $0.47 \pm 0.02 *$ & $0.56 \pm 0.02 *$ & & $0.55 \pm 0.02$ & $0.62 \pm 0.02 *$ & $0.82 \pm 0.02 *$ \\
\hline
\end{tabular}

Values are mean $\pm \mathrm{SE}$. The number of experiments is given after each subheading. For abbreviations see Table I.

${ }^{*} P<0.001$ refers to paired $t$ test comparing changes during and after atrial fibrillation with control values.

$\ddagger P<0.01$ refers to paired $t$ test comparing control values before and after the administration of propranolol or renal denervation.

adrenal arteries. After this injectate hardened, we removed the region en bloc, including the aorta, vena cava, kidney, and adrenal gland. Fat in the specimen was removed by dissection, and after dehydration by ethyl alcohol, and clearing by methyl salicylate, all the small vessels in the region between the adrenal gland and kidney could be easily visualized. Frequently, more than one artery supplied the adrenal gland from the aorta. In the proximity of the gland these arteries gave off a diffuse network of small vessels which entered into the more convex surface of the gland and surrounded it. On the concave surface of the gland small vessels coalesced to form larger vessels between the adrenal gland and kidney, and these vessels then branched and interconnected again over the renal capsule (Fig. 7). The perirenal capsular network also received an inconsistent and variable blood supply from other extra-adrenal sources, but the adreno-renal vessels were seen in all animals studied. The vessels coming from the region of the adrenal gland cephalad to the adrenal vein supplied the upper half of the kidney, and those caudad to the vein supplied the lower half of the kidney (Fig. 7).
Careful removal of the capsule of the kidney revealed 8-12 evenly distributed capsular vessels which penetrated the renal capsule and connected this extrarenal capsular network with the arcuate or interlobar arteries of the kidney (Fig. 7). The capsular vessels were of constant diameter rather than tapering when penetrating the capsule. They distinctly connected the intrarenal arterial vessels with the extrarenal capsular network.

Special experiments concerning the function of the vascular connections between the adrenal glands and the kidneys. Careful observation in vivo of the rete in situ between the adrenal gland and kidney during control periods revealed that these vessels do not pulsate. During atrial fibrillation and during the early postarrhythmic period these vessels appeared increased in size (dilated).

In six dogs a flow probe was placed on each renal artery. After recovery from a control bout of atrial fibrillation $(6 \mathrm{~min})$ in which postarrhythmic renal blood flow was decreased equally on both sides, unilateral selective ligation of the vessels connecting the adrenal gland and kidney was done. Upon cessation of another bout

TABLE V

Effects of Cooling the Cervical Vagi and Atropine $(0.5 \mathrm{mg} / \mathrm{kg}$ ) on Systemic and Renal Hemodynamic Changes during and after Atrial Fibrillation

\begin{tabular}{|c|c|c|c|c|c|c|c|}
\hline & \multicolumn{3}{|c|}{ Pre-vagal cooling } & \multirow[b]{2}{*}{$(n=6)$} & \multicolumn{3}{|c|}{ Vagal cooling } \\
\hline & Control & During & After $4 \mathrm{~min}$ & & Control & During & After $4 \mathrm{~min}$ \\
\hline $\mathrm{MABP}, m m \mathbf{H g}$ & $102 \pm 5$ & $83 \pm 4^{*}$ & $104 \pm 6$ & & $107 \pm 6$ & $83 \pm 5^{*}$ & $106 \pm 6$ \\
\hline $\mathrm{HR}$, beats/min & $150 \pm 8$ & $245 \pm 10^{*}$ & $153 \pm 8$ & & $156 \pm 8$ & $268 \pm 11^{*}$ & $157 \pm 8$ \\
\hline $\mathrm{CO}$, liters/min & $2.53 \pm 0.26$ & $1.97 \pm 0.26^{*}$ & $2.55 \pm 0.26$ & & $2.65 \pm 0.26$ & $1.96 \pm 0.26^{*}$ & $2.66 \pm 0.26$ \\
\hline TPR, $R U$ & $39.5 \pm 4.1$ & $40.6 \pm 4.2$ & $40.0 \pm 4.0$ & & $39.6 \pm 3.8$ & $40.8 \pm 3.8$ & $39.1 \pm 3.8$ \\
\hline $\mathrm{RBF}, \mathrm{ml} / \mathrm{min}$ & $244 \pm 18$ & $175 \pm 10^{*}$ & $185 \pm 10^{*}$ & & $231 \pm 18$ & $157 \pm 10^{*}$ & $230 \pm 11$ \\
\hline $\mathrm{RVR}, r u$ & $0.41 \pm 0.04$ & $0.46 \pm 0.03^{*}$ & $0.55 \pm 0.04^{*}$ & & $0.45 \pm 0.03$ & $0.51 \pm 0.03^{*}$ & $0.45 \pm 0.03$ \\
\hline
\end{tabular}

Values are mean $\pm \mathrm{SE}$. The number of experiments is given after each subheading. For abbreviations see Table $I$.

${ }^{*} P<0.001$ refers to paired $t$ test comparing changes during and after atrial fibrillation with control values. 
TABLE IV (Continued)

\begin{tabular}{|c|c|c|c|c|c|c|}
\hline \multicolumn{3}{|c|}{ Pre-renal denervation } & \multirow[b]{2}{*}{$(n=6)$} & \multicolumn{3}{|c|}{ Renal denervation } \\
\hline Control & During & After $4 \mathrm{~min}$ & & Control & During & After $4 \mathrm{~min}$ \\
\hline $99 \pm 6$ & $81 \pm 6^{*}$ & $99 \pm 7$ & & $102 \pm 6$ & $83 \pm 6^{*}$ & $101 \pm 7$ \\
\hline $140 \pm 8$ & $243 \pm 10^{*}$ & $144 \pm 8$ & & $142 \pm 8$ & $245 \pm 10^{*}$ & $144 \pm 8$ \\
\hline $2.84 \pm 0.25$ & $2.23 \pm 0.24^{*}$ & $2.86 \pm 0.25$ & & $2.80 \pm 0.25$ & $2.21 \pm 0.24^{*}$ & $2.80 \pm 0.25$ \\
\hline $34.2 \pm 2.8$ & $35.0 \pm 2.8$ & $33.9 \pm 2.8$ & & $35.7 \pm 2.8$ & $36.2 \pm 2.8$ & $35.4 \pm 2.8$ \\
\hline $270 \pm 13$ & $190 \pm 12^{*}$ & $208 \pm 12^{*}$ & & $301 \pm 13 \ddagger$ & $238 \pm 12^{*}$ & $235 \pm 12^{*}$ \\
\hline $0.36 \pm 0.02$ & $0.41 \pm 0.02 *$ & $0.47 \pm 0.02 *$ & & $0.33 \pm 0.02 \ddagger$ & $0.34 \pm 0.02$ & $0.42 \pm 0.02 *$ \\
\hline
\end{tabular}

of atrial fibrillation, the kidney on the side of ligation showed no postarrhythmic renal vasoconstriction, while the contralateral kidney showed renal vasoconstriction indistinguishable from the control response in five dogs (Fig. 8). In the sixth animal postarrhythmic renal blood flow was decreased on the side of selective ligation but to a lesser extent than in the control response. Inspection revealed incomplete ligation of the adreno-renal vascular connections. Subsequent total ligation abolished the postarrhythmic renal vasoconstriction (Fig. 8).

Six animals were prepared with a flow probe on the right renal artery. The renal capsule was then stripped from the left kidney, leaving the capsule, its vascular connections, and the adrenal gland intact, and the kidney with its noncapsular vascular connections intact. The stripped left renal capsule was placed in a funnel for collection of blood specimens. A constant intravenous infusion of normal saline was given at $1 \mathrm{ml} / \mathrm{min}$ for replacement of estimated blood loss. The preparation was allowed to stabilize until blood pressure and cardiac output had remained constant for at least $15 \mathrm{~min}$.

Simultaneous control blood samples were collected from the bleeding left renal capsule and the femoral artery. It usually took 1-3 min for a 1-ml collection of the capsular specimen. The femoral artery sample was drawn at the end of the capsular collection period.

Atrial fibrillation was then produced. The hemodynamic response during and after the arrhythmic observed in these animals was indistinguishable from that described previously. Table VII shows the values from the simultaneous left renal capsule and femoral arterial plasma catecholamine samples. A threefold increase from control renal capsular catecholamine concentration was seen during atrial fibrillation and during the postarrhythmic period when maximal postarrhythmic renal vasoconstriction was present $(4 \mathrm{~min}$. postarrhythmia).

Femoral arterial catecholamines were elevated above control immediately after the arrhythmia but not during maximal postarrhythmic renal vasoconstriction. Comparison of simultaneously drawn renal capsule and femoral arterial catecholamines revealed that renal capsular concentrations were significantly higher $(\boldsymbol{P}$ $<0.001)$ during atrial fibrillation and during the postarrhythmic period. During maximal postarrhythmic renal vasoconstriction $(4 \mathrm{~min}$ ) renal capsular catecholamines were threefold higher than femoral arterial levels. Comparison of changes in femoral arterial catecholamine levels in these six dogs in response to atrial fibrillation revealed no significant difference from those seen in the nine animals reported in Table II.

The changes from preintervention control hemodynamics to control hemodynamics during an intervention (SQ 20881, phentolamine, propranolol, vagal cooling, atropine renal denervation, bretylium, and hexamethonium) were the same as have been previously reported in the pentobarbital-anesthetized dog and will not be discussed further unless appropriate to the focus of this study $(10-14)$.

TABLE V (Continued)

\begin{tabular}{|c|c|c|c|c|c|c|}
\hline \multicolumn{3}{|c|}{ Pre-atropine } & \multirow[b]{2}{*}{$(n=6)$} & \multicolumn{3}{|c|}{ Atropine } \\
\hline Control & During & After $4 \mathrm{~min}$ & & Control & During & After $4 \mathrm{~min}$ \\
\hline $107 \pm 8$ & $85 \pm 6^{*}$ & $105 \pm 8$ & & $106 \pm 7$ & $83 \pm 5^{*}$ & $108 \pm 8$ \\
\hline $144 \pm 8$ & $243 \pm 10^{*}$ & $148 \pm 8$ & & $149 \pm 8$ & $260 \pm 11^{*}$ & $150 \pm 8$ \\
\hline $2.30 \pm 0.24$ & $1.84 \pm 0.24^{*}$ & $2.33 \pm 0.24$ & & $2.38 \pm 0.24$ & $1.86 \pm 0.24^{*}$ & $2.40 \pm 0.24$ \\
\hline $45.7 \pm 3.3$ & $44.5 \pm 3.3$ & $44.2 \pm 3.3$ & & $43.7 \pm 3.3$ & $43.0 \pm 3.3$ & $44.1 \pm 3.3$ \\
\hline $225 \pm 15$ & $153 \pm 12 *$ & $166 \pm 12^{*}$ & & $232 \pm 16$ & $160 \pm 12^{*}$ & $170 \pm 15^{*}$ \\
\hline $0.47 \pm 0.03$ & $0.52 \pm 0.03^{*}$ & $0.62 \pm 0.03^{*}$ & & $0.45 \pm 0.03$ & $0.50 \pm 0.03^{*}$ & $0.61 \pm 0.03 *$ \\
\hline
\end{tabular}




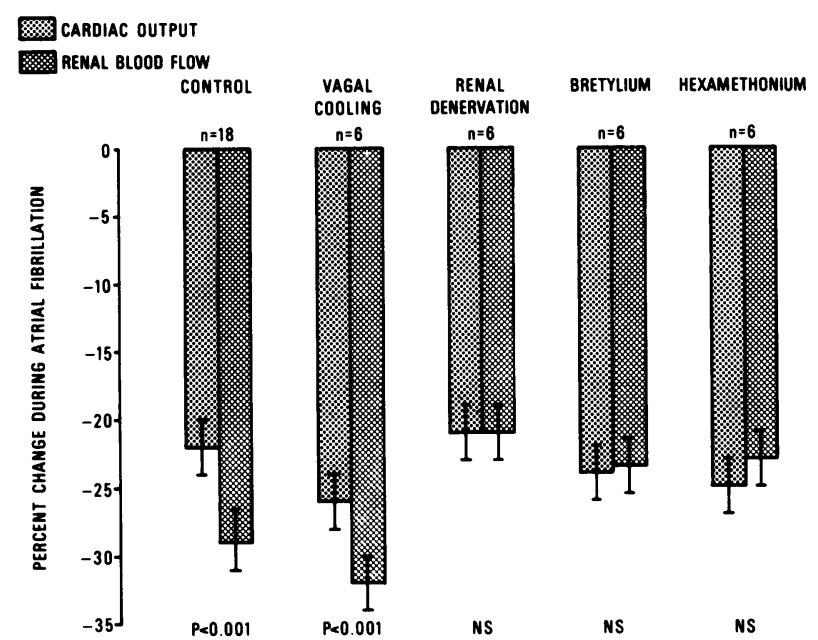

FigURE 5 Effect of vagal cooling, renal denervation, bretylium tosylate $(10 \mathrm{mg} / \mathrm{kg})$, and hexamethonium chloride $(1 \mathrm{mg} / \mathrm{kg})$ on change in renal blood flow, compared with the change in cardiac output during atrial fibrillation.

\section{DISCUSSION}

All arrhythmias induced in this study caused a disproportionately greater reduction of renal blood flow during the hypotension than could be accounted for by the diminished cardiac output. The apparent renal vasoconstriction occurred promptly with the onset of the experimental arrhythmia and required an intact sympathetic nervous system, for it was not observed after renal denervation or the administration of bretylium or hexamethonium. As an explanation for this response (activation of renal sympathetic nerves) one must consider whether the kidney received greater sympathetic stimulation than other vascular beds during the hypotension or whether the renal vascular bed is more responsive to a given level of sympathetic tone than other vascular beds. Similar changes in the dis- $\square$ CONTROL

INTERVENTION

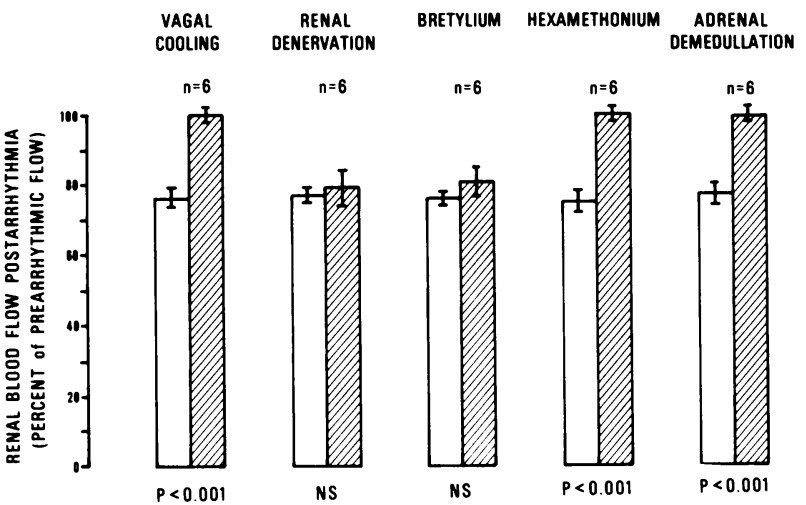

FIGURE 6 Effect of vagal cooling, renal denervation, bretylium tosylate $(10 \mathrm{mg} / \mathrm{kg})$, hexamethonium chloride ( $1 \mathrm{mg} / \mathrm{kg}$ ), and adrenal demedullation on postarrhythmic renal blood flow (percentage of prearrhythmic flow) compared with control response. Renal blood flow measurements represent the mean value during 1 min immediately before atrial fibrillation and during the 4 th min of the postarrhythmic period.

tribution of blood flow have been observed in response to exercise in the conscious dog with complete heart block (15). Because the response of the renal vascular bed during an arrhythmia was not affected by vagal cooling, it suggests that the afferent pathways of this activation of renal sympathetic nerves are not carried in the vagi (16).

After the renal vasoconstriction due to activation of renal sympathetic nerves during experimental arrhythmias and the transient increase in renal blood flow associated with a marked overshoot of cardiac output and blood pressure immediately upon cessation of the arrhythmia, renal blood flow progressively decreased during the postarrhythmic period while cardiac output and arterial pressure returned toward control levels. A reproducible postarrhythmic renal vasoconstrictive

TABLE VI

Effects of Bretylium (10 mg/kg) and Hexamethonium $(1 \mathrm{mg} / \mathrm{kg})$ on Systemic and Renal Hemodynamic Changes during and after Atrial Fibrillation

\begin{tabular}{|c|c|c|c|c|c|c|c|}
\hline & \multicolumn{3}{|c|}{ Pre-bretylium } & \multirow[b]{2}{*}{$(n=6)$} & \multicolumn{3}{|c|}{ Bretylium } \\
\hline & Control & During & After $4 \mathrm{~min}$ & & Control & During & After $4 \mathrm{~min}$ \\
\hline $\mathrm{MABP}, \mathrm{mm} \mathrm{Hg}$ & $110 \pm 6$ & $87 \pm 5^{*}$ & $111 \pm 7$ & & $92 \pm 6 \ddagger$ & $74 \pm 4^{*}$ & $92 \pm 5$ \\
\hline $\mathrm{HR}$, beats/min & $155 \pm 8$ & $245 \pm 10^{*}$ & $154 \pm 8$ & & $138 \pm 7 \ddagger$ & $217 \pm 9 *$ & $137 \pm 7$ \\
\hline $\mathrm{CO}$, liters/min & $2.62 \pm 0.22$ & $2.05 \pm 0.22^{*}$ & $2.62 \pm 0.22$ & & $2.36 \pm 0.20 \ddagger$ & $1.79 \pm 0.20^{*}$ & $2.35 \pm 0.23$ \\
\hline TPR, $R U$ & $41.2 \pm 2.2$ & $40.5 \pm 2.2$ & $41.6 \pm 2.2$ & & $38.1 \pm 2.0 \neq$ & $39.6 \pm 2.0$ & $38.3 \pm 2.0$ \\
\hline $\mathrm{RBF}, \mathrm{ml} / \mathrm{min}$ & $253 \pm 13$ & $172 \pm 12^{*}$ & $195 \pm 12^{*}$ & & $245 \pm 13$ & $187 \pm 12^{*}$ & $188 \pm 12^{*}$ \\
\hline $\mathrm{RVR}, r u$ & $0.43 \pm 0.02$ & $0.48 \pm 0.02 *$ & $0.56 \pm 0.02 *$ & & $0.37 \pm 0.02 \ddagger$ & $0.38 \pm 0.02$ & $0.48 \pm 0.02 *$ \\
\hline
\end{tabular}

Values are mean $\pm \mathrm{SE}$. The number of experiments is given after each subheading. For abbreviations see Table I.

$* P<0.001$ refers to paired $t$ test comparing changes during and after atrial fibrillation with control values.

$\ddagger P<0.01$ refers to paired $t$ test comparing control values before and after the administration of bretylium and hexamethonium. 
response occurred only when cardiac output and mean arterial blood pressure decreased by $>20 \%$ during the preceding arrhythmia, and the arrhythmia lasted at least $4 \mathrm{~min}$. We used atrial fibrillation most frequently in these experiments because the induction of this arrhythmia usually results in an abrupt decrease in cardiac output and blood pressure of about $20 \%$ (2). However, postarrhythmic renal vasoconstriction was not unique to atrial fibrillation for the same postarrhythmic response occurred when atrial or ventricular pacing was rapid enough to produce hypotension. Postarrhythmic renal vasoconstriction has been previously described after atrial fibrillation induced by the epicardial application of aconitine (3). Additionally, atrial fibrillation in the dog whether produced by electrical or aconitine stimulation has been found to have identical electrical activity (17). This suggests that the method of inducing atrial fibrillation is not an important determinant of whether postarrhythmic renal vasoconstriction occurs. Our experiments indicate that the magnitude (and duration) of hemodynamic changes resulting from an experimental arrhythmia is the more important determinant of whether postarrhythmic renal vasoconstriction occurs.

The postarrhythmic renal vasoconstrictive response occurred in an all or none fashion depending on the changes in mean arterial pressure and cardiac output produced during the arrhythmia (Figs. 2 and 3). This could be interpreted as reflecting the threshold of a cardiac volume receptor or baroreceptor reflex response $(16,18)$. Because the postarrhythmic decrease in renal blood flow was observed after muscarinic receptor blockade with atropine but not observed after cooling the cervical vagi, this would suggest that either cardiac or aortic mechanoreceptors whose afferent pathways ascend through the vagi are primarily involved in central modulation of the postarrhythmic sympathetic response. Although the same postarrhythmic renal vascular response was observed after both atrial and ventricular arrhythmias, further experiments would be required to determine whether these receptors are primarily cardiac or aortic in location (16, 18-20).

Postarrhythmic renal blood flow decreased progres- sively and later returned gradually to control levels of flow. This pattern of change as well as the fact that the decreased postarrhythmic renal blood flow occurred despite renal denervation suggested that postarrhythmic renal vasoconstriction was humorally mediated rather than through activation of renal sympathetic nerves. Plasma renin activity was not increased during postarrhythmic renal vasoconstriction, and postarrhythmic renal vasoconstriction occurred despite an intrarenal infusion of converting enzyme inhibitor sufficient to block the pressor response of a test dose of angiotensin I. These results suggest that postarrhythmic renal vasoconstriction was not mediated by angiotensin II.

Alpha adrenergic receptor blockade with phentolamine and ganglionic blockade by hexamethonium chloride (but not selective inhibition of postganglionic sympathetic nervous system activity by bretylium tosylate) prevented postarrhythmic renal vasoconstriction. The administration of propranolol intensified the postarrhythmic vasoconstrictive response. These findings suggested that the response was mediated primarily through alpha adrenergic stimulation by adrenal catecholamines (11). The significant elevation of inferior vena caval catecholamine concentration during atrial fibrillation suggested that adrenal catecholamines had indeed been released. However, femoral arterial catecholamine levels were not elevated during the period of maximal postarrhythmic renal vasoconstriction. The rapid postarrhythmic return to control cardiac output and mean arterial blood pressure was consistent with these arterial catecholamine measurements. These findings, therefore, suggested that adrenal catecholamines might reach the kidney via localized pathways and thus affect control of the renal circulation without entering the systemic circulation. Both epinephrine and norepinephrine have been shown to cause constriction of the renal arteriole (21).

Anatomical demonstration of a rete between the adrenal gland and kidney in each dog provided a direct route by which adrenal catecholamines could reach the kidney in a higher concentration than other organs. A similar adreno-renal vascular network has

TABLE VI (Continued)

\begin{tabular}{|c|c|c|c|c|c|c|}
\hline \multicolumn{3}{|c|}{ Pre-hexamethonium } & $(n=6)$ & \multicolumn{3}{|c|}{ Hexamethonium } \\
\hline $142 \pm 8$ & $235 \pm 10^{*}$ & $145 \pm 8$ & & $118 \pm 6 \ddagger$ & $195 \pm 8^{*}$ & $119 \pm 6$ \\
\hline $3.05 \pm 0.22$ & $2.38 \pm 0.21^{*}$ & $3.04 \pm 0.22$ & & $2.44 \pm 0.20 \ddagger$ & $1.87 \pm 0.20^{*}$ & $2.46 \pm 0.23$ \\
\hline $36.7 \pm 1.9$ & $36.2 \pm 1.9$ & $36.5 \pm 1.9$ & & $32.0 \pm 1.8 \ddagger$ & $31.5 \pm 1.8$ & $32.0 \pm 1.8$ \\
\hline
\end{tabular}




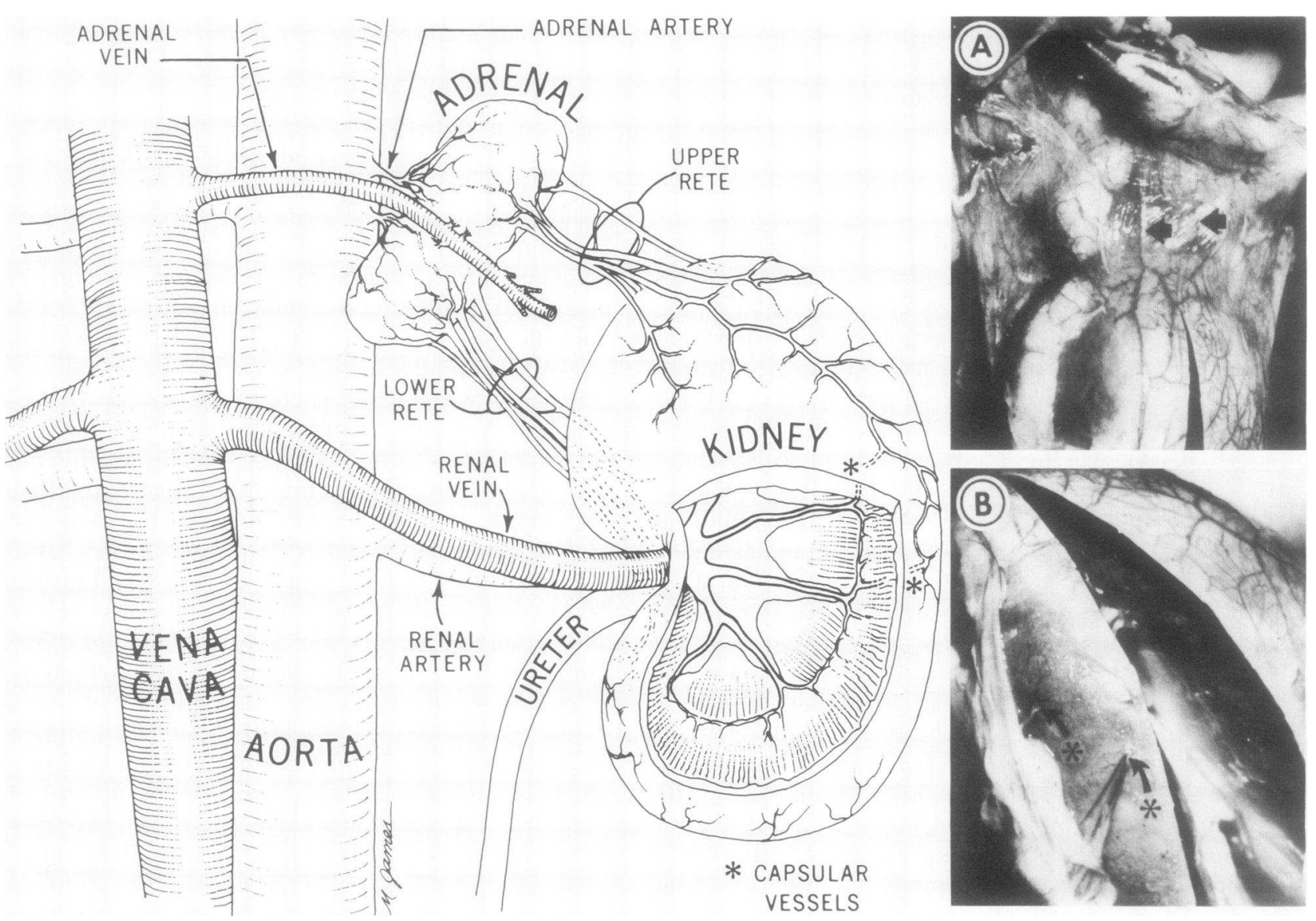

FIGURE 7 The drawing depicts the left kidney and adrenal gland from one of the specimens prepared in the dog to demonstrate the adreno-renal vascular network. The rete are drawn slightly larger in scale for demonstration purposes. The intrarenal veins were omitted from the cut away section of the kidney to simplify a demonstration of how the capsular vessels (asterisks) connect the extrarenal capsular vascular network with the intrarenal arterial system (arcuate or interlobar arteries) at the level of the corticomedullary junction. (A) Photograph of the adreno-renal vascular network from a specimen prepared by selective injection of Microfil into an adrenal artery. Note the adrenal gland bisected along its short axis (upper part of photograph). Note also the rete (arrows). (B) Photograph of the same specimen as (A) with the renal capsule lifted off the kidney to demonstrate the capsular vessels penetrating the renal cortex (arrows with asterisks).

previously been described in the cat (6). The markedly elevated catecholamine concentrations found in renal capsular blood and the abolition of postarrhythmic renal vasoconstriction by selective ligation of the rete confirm the functional capacity of this vascular network in the dog.

Dilatation of the rete both during atrial fibrillation and during the postarrhythmic period could have a neurogenic basis or could be due to the development of a pressure gradient between the adrenal and renal vascular beds. An understanding of the mechanism by which rete dilatation occurs would require further studies. However it occurred, dilatation of the rete could facilitate the flow of catecholamines into this vascular network. Postarrhythmic renal vasoconstriction was not observed after arrhythmias lasting $<4 \mathrm{~min}$, suggesting that a period of time is required before catecholamines reach the kidney via this pathway in sufficient concentrations to cause vasoconstriction.

After the sympathetic discharge due to arrhythmiainduced hypotension, the temporarily increased femoral arterial catecholamine concentrations decreased rapidly toward control while catecholamine concentrations in the renal capsule remained elevated for a period coinciding with the prolonged postarrhythmic renal vasoconstriction. The prolonged elevation of catecholamines in this vascular network cannot be explained as a persistent effect of an abbreviated sympathetic neural discharge, because catecholamines are rapidly metabolized or taken up by adrenergic nerves (22). 

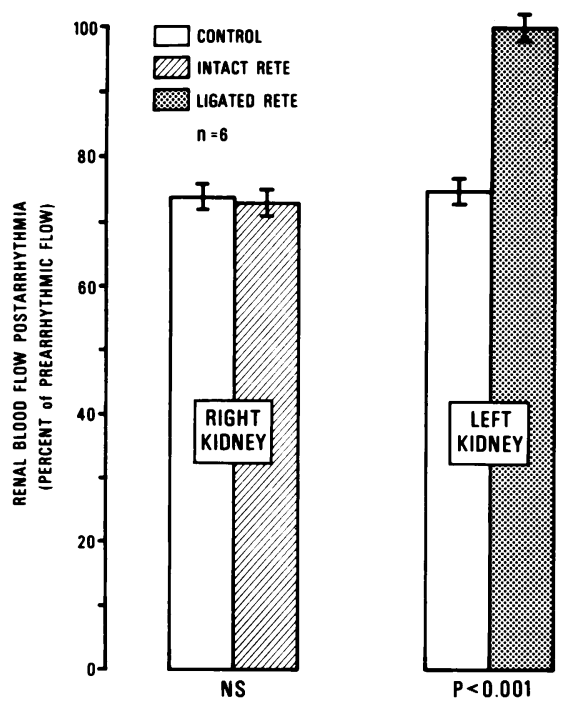

Figure 8 Effect of selective ligation of the rete between the left adrenal gland and kidney compared with control response and in intact rete on the right side.

Alternatively, one may postulate continued release from the adrenal gland in the presence of slow flow through the rete and relatively little dilution. Further studies are needed to determine the stimulus for continued release of catecholamines from the adrenal medulla during the postarrhythmic period because blood pressure and cardiac output have returned to control levels.

Acute experiments in dogs demonstrate that stepwise increases in doses of norepinephrine infused directly into the kidney cause a stepwise decrease in renal blood flow (21). We observed no progressive diminution of renal blood flow despite repetitive production of arrhythmias at $15-\mathrm{min}$ intervals, suggesting that the concentration of catecholamines in the rete changed little after each bout of atrial fibrillation. However, the persistent decrease in renal blood flow throughout $2 \mathrm{~h}$ of repeated bouts of atrial fibrillation (every $15 \mathrm{~min}$ ) supports previous observations that the renal vascular bed does not develop tachyphylaxis to the vasoconstricting effects of norepinephrine (23).

In the conscious dog arterial norepinephrine concentration is reported to be higher than epinephrine concentration under basal conditions (24). We found that under control conditions femoral arterial epinephrine concentrations tended to be higher than norepinephrine concentrations and that both norepinephrine and epinephrine concentrations in the adrenal venous effluent or renal capsule tended to be higher than in arterial blood. These differences were not statistically significant because of large standard deviations, perhaps due to the effects of anesthesia and surgical trauma. However, the trends suggest that there is adrenal medullary catecholamine release under basal conditions in the pentobarbital-anesthetized dog surgically prepared for study. Pentobarbital anesthesia has been shown to enhance the response of the renal vascular bed to the vasoconstricting effects of catecholamines and to blunt the vasoconstricting effects of angiotensin II in the dog when compared to conscious animals (25). Despite these differences the renal vascular bed of both anesthetized and conscious dogs responds to catecholamines with vasoconstriction $(21,23)$. Further studies are necessary to assess the magnitude of participation of the adreno-renal vascular

TABLE VII

Plasma Norepinephrine Concentration (NE) and Plasma Epinephrine Concentration (E) Collected from the Left Renal Capsule (RC) and the Femoral Artery (FA) during and after a Bout of Atrial Fibrillation in Six Anesthetized Dogs

\begin{tabular}{cccccc}
\hline \multirow{2}{*}{$\begin{array}{c}\text { Sample and } \\
\text { site }\end{array}$} & $\begin{array}{c}\text { Control before } \\
\text { arrhythmia }\end{array}$ & $\begin{array}{c}\text { During atrial } \\
\text { fibrillation }\end{array}$ & \multicolumn{2}{c}{ Time after arrhythmia } \\
\cline { 4 - 6 } & Immediate & 4 min & 25 min \\
\hline RC & $391.7 \pm 56.8$ & $1,069.4 \pm 73.5^{*}$ & $963.7 \pm 71.6^{*}$ & $842.1 \pm 69.2^{*}$ & $497.3 \pm 58.4$ \\
NE, $p g / m l$ & $\mathrm{NS}$ & $P<0.001$ & $P<0.01$ & $P<0.001$ & $P<0.05$ \\
FA & $254.3 \pm 43.3$ & $336.6 \pm 44.4$ & $448.0 \pm 57.1 \ddagger$ & $269.4 \pm 53.8$ & $265.2 \pm 40.2$ \\
& & & & \\
RC & $404.4 \pm 54.5$ & $1,327.7 \pm 84.1^{*}$ & $1,199.5 \pm 75.7^{*}$ & $948.1 \pm 71.3^{*}$ & $513.4 \pm 58.9$ \\
E, $p g / m l$ & $\mathrm{NS}$ & $P<0.001$ & $P<0.01$ & $P<0.01$ & $P<0.05$ \\
FA & $332.1 \pm 52.7$ & $396.1 \pm 54.1$ & $506.2 \pm 58.3 \pm$ & $403.6 \pm 55.6$ & $317.4 \pm 51.8$ \\
\end{tabular}

Values are mean $\pm \mathrm{SE}$. Maximal postarrhythmic renal vasoconstriction was present when the 4-min samples were collected. Postarrhythmic renal blood flow had returned to control levels of flow when the 25-min samples were collected.

${ }^{*} P<0.01$ refer to changes compared to control.

$\ddagger P<0.05$ refer to changes compared to control. 
pathway in the control of renal blood flow in the conscious dog.

Because either stimulation of the renal nerves or intrarenal infusion of epinephrine or norepinephrine promotes renal retention of sodium in the dog $(23,26-28)$, the renal vasoconstriction seen in the present experiments by activation of the renal sympathetic nerves during an arrhythmia and by adrenal catecholamines via the adreno-renal network after an arrhythmia may be important mechanisms by which the kidney maintains vascular volume. During an arrhythmia, the renal vascular bed was relatively more constricted than the general circulation, suggesting proportionally greater sympathetic activity in the kidney. Others have found that during increased sympathetic nervous system activity, there is a loss of intravascular fluid into the perivascular tissue of several vascular beds (29). Perhaps postarrhythmic renal vasoconstriction allows time for resorption of fluid back into the vascular space. Further study is needed to test this hypothesis.

Despite the rather long duration of arrhythmiainduced hypotension required for its consistent production, postarrhythmic renal vasoconstriction has many features suggesting that it is a reflex response (30). For example, it occurred in an all or none fashion depending on the magnitude of changes in mean arterial pressure and cardiac output produced during the arrhythmia. Whereas renal denervation or atropine or bretylium failed to alter the postarrhythmic renal vasoconstriction, three different interventions were equally effective in eliminating it entirely. They were the administration of hexamethonium, or the ligation of the adreno-renal rete or vagal cooling. Although atropine blocks muscarinic receptors (thus blocking parasympathetic efferent neural effects), it does not alter adrenal catecholamine release mediated by nicotinic receptors. Thus, the postarrhythmic renal vasoconstrictive response depends on the necessary release of adrenal catecholamines and an intact system of adreno-renal vessels or rete, and it requires vagal participation for afferent neural traffic involved in central modulation of a postarrhythmic sympathetic response (30). The intrarenal infusion of phentolamine also prevented postarrhythmic renal vasoconstriction. Phentolamine has both alpha receptor blocking and direct smooth muscle vasodilating properties. We would anticipate that an infusion of any vasodilator in sufficient dosage into the renal vascular bed would reverse postarrhythmic renal vasoconstriction. Further studies are needed to know whether this adreno-renal vascular connection functions in other cardiovascular responses and whether the situation exists comparably in other animals, especially man.

\section{ACKNOWLEDGMENTS}

Bretylium tosylate was supplied by Arnar-Stone Laboratories, Inc., Mount Prospect, Ill. SQ 20881 was given to us by Squibb Institute, New Brunswick, N. J.

This work was supported by the National Heart, Lung, and Blood Institute (Program Project grant HL 11310, ROl-22554, and Specialized Center of Research on Ischemic Heart Disease grant 1, P17 HL 17667), and by the Rast Fund for Medical Research.

\section{REFERENCES}

1. Wood, P. 1968. Diseases of the Heart and Circulation. J. B. Lippincott Co., Philadelphia, Pa. 226-290.

2. Corday, E., and T. Lang. 1974. Hemodynamic consequences of cardiac arrhythmias. In The Heart: Arteries and Veins. J. W. Hurst, R. B. Logue, R. C. Schlant, N. K. Wenger, editors. McGraw-Hill Book Company, New York. 3rd edition. 498-502.

3. Irving, P. W., and E. Corday. 1961. Effect of the cardiac arrhythmias on the renal and mesenteric circulation. Am. J. Cardiol. 8: 32-40.

4. Oparil, S., and E. Haber. 1974. The renin-angiotensin system. N. Engl. J. Med. 291: 389-401, 446-457.

5. Block, M. A., K. G. Wakim, and F. C. Mann. 1952. Renal function during stimulation of renal nerves. Am.J. Physiol. 169: 670-677.

6. Cow, D. 1914. The suprarenal bodies and diuresis. J. Physiol. (Lond.). 48: 443-452.

7. Peuler, J. D., and G. A. Johnson. 1975. A sensitive radioenzymatic assay of plasma catecholamines: Initial studies in supine normotensive subjects. Clin. Res. 23: 474A. (Abstr.)

8. Haber, E., T. Koerner, L. B. Page, B. Kliman, and A. Purnode. 1969. Application of a radioimmunoassay for angiotensin I to the physiologic measurements of plasma renin activity in normal human subjects: Renin activity by angiotensin I radioimmunoassay. J. Clin. Endocrinol. Metab. 29: 1349-1355.

9. Downie, N. M., and R. W. Heath. 1970. Basic Statistical Methods. Harper and Row Publishers, Inc., New York. 167-187.

10. Bailie, M. D., and J. A. Barbour. 1975. Effect of inhibition of peptidase activity on distribution of intrarenal blood flow. Am. J. Physiol. 228: 850-853.

11. Nickerson, M., and B. Collier. 1975. Drugs inhibiting adrenergic nerves and structures innervated by them. In The Pharmacological Basis of Therapeutics. L. S. Goodman and A. Gilman, editors. Macmillan Publishing Co., Inc., New York. 5th edition. 553-564.

12. Clement, D. L., C. L. Pelletier, and J. T. Shepherd. 1972. Role of vagal efferents in the control of renal sympathetic nerve activity in the rabbit. Circ. Res. 31: 824-830.

13. Urthaler, F., B. L. Krames, and T. N. James. 1974. Selective effects of pentobarbital on automaticity and conduction in the intact canine heart. Cardiovasc. Res. 8: 46-57.

14. Smith, H. W. 1951. The control of the renal circulation and the action of pharmacodynamic agents. In The Kidney: Structure and Function in Health and Disease. Oxford University Press, New York. 411-460.

15. Vatner, S. F., C. B. Higgins, S. White, T. Patrick, and D. Franklin. 1971. The peripheral vascular response to severe exercise in untethered dogs before and after complete heart block. J. Clin. Invest. 50: 1950-1960. 
16. Kirchheim, H. R. 1976. Systemic arterial baroreceptor reflexes. Physiol. Rev. 56: 100-176.

17. Prinzmetal, M., E. Corday, I. C. Brill, R. W. Oblath, and H. E. Kruger. 1952. The Auricular Arrhythmias. Charles C. Thomas, Publisher, Springfield, Ill. 243-257.

18. Linden, R. J. 1973. Function of cardiac receptors. Circulation. 48: 463-480.

19. Donald, D. E., and A. J. Edis. 1971. Comparison of aortic and carotid baroreflexes in the dog. J. Physiol. (Lond.). 215: 521-538.

20. Paintal, A. S. 1973. Vagal sensory receptors and their reflex effects. Physiol. Rev. 53: 159-227.

21. Wathen, R. L., W. S. Kingsbury, D. A. Stouder, E. G. Schneider, and H. H. Rostorfer. 1965. Effects of infusion of catecholamines and angiotensin II on renin release in anesthetized dogs. Am.J. Physiol. 209: 1012-1024.

22. Iversen, L. L. 1967. The uptake and storage of noradrenaline. In Sympathetic Nerves. Harvard University Press, Cambridge, Mass. 108-135.

23. Katholi, R. E., R. M. Carey, C. R. Ayers, E. D. Vaughan, Jr., M. R. Yancey, and C. L. Morton. 1977. Production of sustained hypertension by chronic intrarenal norepinephrine infusion in conscious dogs. Circ. Res. 40(suppl. I): $118-126$.
24. Buhler, H. U., M. D. Prada, W. Haefely, and G. B. Picotti. 1978. Plasma adrenaline, noradrenaline and dopamine in man and different animal species. J. Physiol. (Lond.). 276: 311-320.

25. Burger, B. M., T. Hopkins, A. Tulloch, and N. K. Hollenberg. 1976. The role of angiotensin in the canine renal vascular response to barbiturate anesthesia. Circ. Res. 38: 196-202.

26. Di Bona, G. F. 1974. Neural control of renal tubular sodium reabsorption in the dog.Fed. Proc. 37: 1214-1217.

27. Schrier, R. W. 1974. Effects of adrenergic nervous system and catecholamines on systemic and renal hemodynamics, sodium and water excretion and renin secretion. Kidney Int. 6: 291-306.

28. Barger, A. C., F. P. Muldowney, and M. R. Liebowitz. 1959. Role of the kidney in the pathogenesis of congestive heart failure. Circulation. 20: 273-285.

29. Cohn, J. N. 1966. Relationship of plasma volume changes to resistance and capacitance vessel effects of sympathomimetic amines and angiotensin in man. Clin. Sci. (Oxf.). 30: 267-278.

30. Heymans, C., and E. Neil. 1958. Reflexogenic areas of the cardiovascular system. Little, Brown and Company, Boston, Mass. 18-25, 42-44. 